\title{
Diabetes mellitus in North West Ethiopia: a community based study
}

\author{
Solomon Mekonnen Abebe ${ }^{1 *}$, Yemane Berhane ${ }^{2}$, Alemayehu Worku ${ }^{3}$ and Abebayehu Assefa ${ }^{4}$
}

\begin{abstract}
Background: Diabetes mellitus is recognized as one of the emerging public health problems in developing countries. However, its magnitude has not been studied at community levels, making the provision of appropriate services difficult in such countries. Hence, this study aimed to compare the magnitude and associated risks of diabetes mellitus among urban and rural adults in northwest Ethiopia.

Methods: A cross-sectional population based survey was performed using the WHO STEPwise method on adults aged 35 years and above. A multistage cluster random sampling strategy was used to select study participants from urban and rural locations. Fasting blood glucose levels were determined using peripheral blood samples by finger puncture. Prevalence was computed with a 95\% confidence interval for each residential area. Selected risk factors were assessed using logistic regression.
\end{abstract}

Results: The prevalence of diabetes mellitus among adults aged 35 years and above was $5.1 \%$ [95\% Cl: 3.8, 6.4] for urban and 2.1\% [95\% Cl: 1.2, 2.9] for rural dwellers. The majority (69\%) of the identified diabetic cases were not diagnosed prior to the survey. The highest proportion (82.6\%) of the undiagnosed cases was noted among the rural population and $63 \%$ among the urban population. Family history of diabetes ( $A O R=5.05 ; 2.43$, 10.51), older age $(A O R=4.86 ; 1.99,11.9)$ and physical inactivity $(A O R=1.92 ; 1.06,3.45)$ were significantly associated with diabetes mellitus among the urban population. Alcohol consumption ( $A O R=0.24,0.06,0.99$ ) was inversely associated with diabetes mellitus in rural areas.

Conclusion: The prevalence of diabetes mellitus is considerably high among the urban compared to the rural population. Diabetes is largely undiagnosed and untreated, especially in rural settings. Appropriate actions need to be taken to provide access to early diagnosis and treatment in order to reduce associated complications.

\section{Background}

Diabetes Mellitus (DM) is a metabolic disorder characterized by chronic hyperglycemia [1]. The global burden of diabetes has increased twelve fold between 1985 and 2011[2,3]. The International Diabetes Federation (IDF) suggests that the number of adults living with diabetes worldwide will further expand by $50.7 \%$ by 2030 [2]. Evidence shows that DM is claiming the lives of more than 4 million people worldwide annually and developing countries account for a substantially high proportion [4].

According to the 2011 report of the International Diabetes Federation (IDF), the number of adults living with diabetes in Ethiopia was 3.5\% [3]. A study done on

\footnotetext{
* Correspondence: solomekonnen@yahoo.com

${ }^{1}$ Department of Physiotherapy, College of Medicine and Health Sciences, University of Gondar, Gondar, Ethiopia

Full list of author information is available at the end of the article
}

urban Commercial Bank employees in Ethiopia showed a 6.5\% prevalence of DM [5] which indicated the significance of lifestyle for DM etiology. However, populationbased estimations, especially for rural settings are lacking.

Physical activity and over-weight have not received much importance in the daily life of the urban population in Africa due to the prevailing inadequate road infrastructure necessitating long distance walking on a daily basis. However, with the progressive improvement in roads, the adoption of western lifestyle, and the rising number of ageing population, people in urban areas are more prone to developing diabetes [6]. So far, most of the diabetes mellitus studies in Ethiopia were institution-based and urban focused with no studies of rural dwellers. Hence, population-based epidemiological information from both urban and rural populations is essential to understand the whole picture of DM in Ethiopia [5,7-9] to help expand service availability and

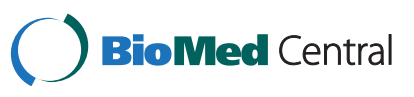


appropriate clinical intervention. Therefore, assessing and comparing the prevalence of DM in the urban and rural areas of Ethiopia is imperative in order to inform, in particular, the governmental and clinical decision makers [10]. The objective of the study was thus to assess the prevalence and associated risk factors of DM among rural and urban dwellers in northwest, Ethiopia.

\section{Methods}

\section{Study population}

This study was conducted in two residential settings in the town of Gondar and in a largely rural district of Dabat. Gondar town has an estimated population of 210,000 and is one of the largest towns of the country [11]. The rural district of Dabat DHSS has an estimated population of 44,723 that is largely living on subsistance farming [12].

The study utilized a comparative cross-sectional community-based design. All permanent residents in the study area who were 35 years and older were eligible to participate in the study.

The sample size for the study was determined by assuming the prevalence of urban DM to be $2.0 \%$ and that of rural DM to be $0.5 \%$ [13]. A power of $80 \%$ was used to detect the difference indicated between the urban and rural populations, with a $95 \%$ confidence level and $10 \%$ of non-response rate. Accordingly, the calculated sample size was 1100 for urban and 1100 for rural settings [14]. A multistage cluster random sampling strategy was used to select study participants from urban and rural locations. Initially, clusters targeting the smallest administrative units in Ethiopia called 'Kebele' were selected using simple random sampling after obtaining the list from the district administration. Then, households were selected within each cluster using the systematic random sampling technique. Finally, one eligible adult was selected from each household using simple random sampling.

\section{Data collection}

Data were collected by interviewing eligible subjects using a pretested and structured questionnaire. The questionnaire, which was in the local language, included questions that assessed diabetic risk factors. Fasting blood glucose was measured as per the WHO recommendations [15]. Peripheral blood samples by finger puncture were collected early in the morning before participants took their breakfast. The WHO and IDA criteria were used to classify fasting blood glucose levels [16,17]. Anthropometric measurements were taken using standardized techniques and calibrated equipment. Subjects were weighed to the nearest $0.1 \mathrm{~kg}$ in light indoor clothing and bare feet or with stockings. Height was measured using a stadiometer; participants stood in erect posture without shoes, and the results were recorded to the nearest $0.5 \mathrm{~cm}$. Measures were taken two times, and the average was considered in the analysis. Body mass index (BMI) was calculated as the ratio of weight in kilograms to the square of height in meters. Waist girth was measured by placing a plastic tape to the nearest $0.5 \mathrm{~cm}$ horizontally, midway between the 12 th rib and iliac crest on the mid-axillary line. Hip circumference was measured around the widest portion of the buttocks, with the tape parallel to the floor [18].

House-to-house data collection was performed by trained field workers. The field study team was composed of enumerators, laboratory technicians, nurses, and supervisors. All were trained by the principal investigator for three days on the study procedures. To ensure the quality of the interview and the acquisition of quality data, random checks were carried out by the principal investigator.

\section{Data analysis}

Double data entry procedures were done using the EPI Info statistical software. The prevalence estimations for urban and rural subjects were made separately by sex. The prevalence estimation was made along with a 95\% confidence interval (CI). The results were considered statistically significant at $\mathrm{P} \leq 0.05$. Logistic regression was applied to identify risk factors for urban and rural participants separately. The independent variables were selected based on prior evidence in the literature and their effect in current analysis. Independent variables with a p-value of 0.20 and less during the bivariate test were then included in the multivariable logistic regression model.

Statistical analysis was performed using the STATA version 11 software. Fasting plasma glucose (FPG) > $126 \mathrm{mg} / \mathrm{dl}$ was used to make the diagnosis of DM, which was confirmed by repeating the test on another day [15].Waist circumference (WC) was categorized as low risk if it was $93.9 \mathrm{~cm}$ or less for men, and $79.9 \mathrm{~cm}$ or less for women; high risk if it was $94 \mathrm{~cm}$ or more for men, and $80 \mathrm{~cm}$ or more for women [19].

Study participants were recruited voluntarily after obtaining full information about the study and signing a written consent agreement. They were informed of their rights to withdraw from the study at any stage. Individuals identified as cases of DM were referred to the nearby clinic for further treatment and follow-up. The protocol and written consent was approved by the Institutional Review Board of the University of Gondar.

\section{Results}

A total of 1100 study participants were initially enrolled from each urban and rural setting, but some refused to give a blood sample, and were excluded. The respondent rate was $97.3 \%$. Thus, 1050 study subjects from urban and 1091 rural areas were included in the analysis. The Mean age $( \pm \mathrm{SD})$ of the urban population was $49.9( \pm 12)$ years and that of the rural population was $46.6( \pm 3)$ years. The sociodemographic and life style characteristics of the study participants were stratified by sex and residence (Table 1). 
Table 1 Socio-demographic characteristics of the study population by residence and sex for adults age 35 and above years, North West Ethiopia, 2012

\begin{tabular}{|c|c|c|c|c|c|}
\hline \multirow{3}{*}{ Variable } & \multicolumn{4}{|c|}{ Study participant } & \multirow[t]{3}{*}{ Diabetic case $\mathrm{n}(\%)$} \\
\hline & \multicolumn{2}{|c|}{ Urban } & \multicolumn{2}{|c|}{ Rural } & \\
\hline & Male n (\%) & Female $\mathrm{n}(\%)$ & Male n (\%) & Female n (\%) & \\
\hline \multicolumn{6}{|l|}{ Age group (years) } \\
\hline $35-44$ & $142(40.5)$ & $265(37.9)$ & $280(44.4)$ & $215(46.6)$ & $20(2.22)$ \\
\hline $45-54$ & $99(28.2)$ & $201(28.8)$ & $159(25.2)$ & $107(23.2)$ & $16(2.83)$ \\
\hline $55-64$ & $39(11.1)$ & $139(19.9)$ & $103(16.4)$ & 84 (18.2) & $21(5.75)$ \\
\hline$\geq 65$ & $71(20.2)$ & $94(13.5)$ & $88(13.9)$ & $55(11.9)$ & $20(6.49)$ \\
\hline \multicolumn{6}{|l|}{ Religion } \\
\hline Orthodox & 311 (89.9) & $654(94.5)$ & $624(99.1)$ & $455(98.7)$ & $73(3.57)$ \\
\hline Muslim & $32(9.2)$ & $36(5.2)$ & $6(0.9)$ & $6(1.3)$ & $4(5.00)$ \\
\hline Others & $3(0.9)$ & $2(0.3)$ & $0(0.00)$ & $0(0.00)$ & $0(0.00)$ \\
\hline \multicolumn{6}{|l|}{ Level of education } \\
\hline Non formal school & 137 (39) & $438(62.7)$ & $544(86.4)$ & $437(62.7)$ & $57(3.66)$ \\
\hline Grade 1-6 & $23(6.6)$ & $50(7.2)$ & 75 (11.9) & $20(4.3)$ & $8(4.76)$ \\
\hline Grade $7-12$ & $102(29.1)$ & $138(19.7)$ & $9(1.4)$ & $3(0.65)$ & $6(2.38)$ \\
\hline Diploma and above & $68(19.4)$ & $20(2.9)$ & $1(0.2)$ & $0(0.00)$ & $4(5.80)$ \\
\hline Refused & $21(5.9)$ & $53(7.6)$ & $1(0.2)$ & $1(0.22)$ & $4(3.23)$ \\
\hline \multicolumn{6}{|l|}{ Marital status } \\
\hline Never married & $36(10.3)$ & $49(7.02)$ & $5(0.8)$ & $0(0.00)$ & $4(4.44)$ \\
\hline Currently married & $269(77.1)$ & $412(59)$ & $608(96.5)$ & $278(60.3)$ & $52(3.32)$ \\
\hline Separated & $18(5.2)$ & $47(6.7)$ & $1(0.2)$ & $5(1.1)$ & $6(8.45)$ \\
\hline Divorced & $9(2.6)$ & $60(8.6)$ & $6(0.95)$ & $34(7.4)$ & $6(5.5)$ \\
\hline Widowed & $10(1.6)$ & 129 (18.5) & $10(1.6)$ & $144(31.2)$ & $9(3.01)$ \\
\hline \multicolumn{6}{|l|}{ BMI kg/m2 } \\
\hline$\leq 18$ & $26(7.4)$ & $80(11.5)$ & $183(29.1)$ & $155(33.7)$ & $8(1.8)$ \\
\hline $18-24$ & $257(73.2)$ & $460(66)$ & $435(69.1)$ & $299(65)$ & 49 (3.38) \\
\hline 25 and above & $68(19.4)$ & $157(22.6)$ & $12(1.9)$ & $6(1.3)$ & $19(7.82)$ \\
\hline \multicolumn{6}{|l|}{ Family history } \\
\hline Yes & $39(5.6)$ & 35 (10.03) & $4(0.9)$ & $0(0.00)$ & 14 (17.95) \\
\hline No & $658(94.4)$ & 314 (89.97) & $456(99.1)$ & $630(100)$ & $63(3.06)$ \\
\hline \multicolumn{6}{|l|}{ Smoking } \\
\hline Yes & $18(5.1)$ & $0(0.00)$ & $5(0.8)$ & $1(0.22)$ & $0(0.00)$ \\
\hline No & 333 (94.9) & $697(100)$ & $625(99.2)$ & $460(99.8)$ & 77 (3.64) \\
\hline \multicolumn{6}{|c|}{ Alcoholic drink within the past 30 day } \\
\hline Yes & $140(39.9)$ & $104(14.9)$ & $619(98.2)$ & $441(95.7)$ & $27(2.07)$ \\
\hline No & $211(60.1)$ & $595(85.1)$ & $11(1.75)$ & $20(4.3)$ & $50(5.97)$ \\
\hline \multicolumn{6}{|c|}{ Frequency of eating fruit in a typical week } \\
\hline Not eating & $56(16.1)$ & $134(19.4)$ & $625(99.4)$ & $455(98.7)$ & $31(2.44)$ \\
\hline $1-3$ times & $279(79.9)$ & $530(76.6)$ & $4(0.6)$ & $4(0.9)$ & $41(5.02)$ \\
\hline 4-7 times & $14(4.01)$ & $28(4.1)$ & $0(0.00)$ & $2(0.43)$ & $3(6.82)$ \\
\hline \multicolumn{6}{|c|}{ Frequency of eating vegetables in a typical week } \\
\hline Not eating & $19(5.5)$ & $43(6.2)$ & $628(99.7)$ & $456(98.9)$ & $25(2.18)$ \\
\hline $1-3$ times & $265(77.3)$ & $492(70.7)$ & $2(0.32)$ & $4(0.9)$ & 37 (4.82) \\
\hline 4-7 times & $60(17.2)$ & $161(23.1)$ & $0(0.00)$ & $1(0.22)$ & 15 (6.76) \\
\hline
\end{tabular}




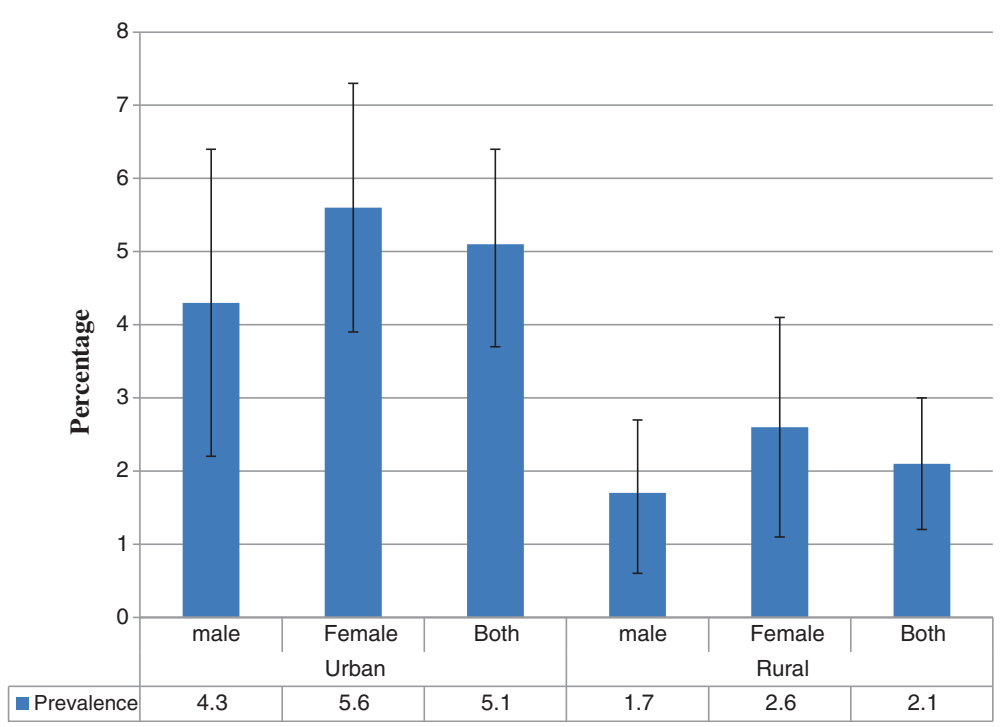

Figure 1 Prevalence of diabetes mellitus by residence and sex with $95 \% \mathrm{Cl}$ error bar among adults age 35 and above years, North West Ethiopia, 2012.

About $8.8 \%$ of the study population was overweight, and $2.5 \%$ was obese. Over-weight and obesity were higher among the urban community $(21.5 \%)$ than the rural ones (1.66\%). The proportion was higher $(22.6 \%)$ among females than males (19.4\%) in the urban community. The proportion was low (1.9\%) among males and $(1.3 \%)$ among females in the rural community. The proportion with abdominal obesity was high (37.7\%) among urban subjects than the rural subjects $(25 \%)$. The proportion was higher among women (49.1\%) than men (10.2\%). The proportion of alcohol drinking during the last 30 days in the study population was higher among rural males $(98.2 \%)$ and females $(95.7 \%)$ than the urban males (39.9\%) and females (14.9\%). The proportion of cigarette smoking among the study group was very low
(1.1\%). In a typical week, $3.6 \%$ ate fruit; the highest proportion (7.08\%) was noted among urban residents and a very low proportion $(0.37 \%)$ among rural dwellers (Table 1).

\section{Prevalence of diabetes mellitus}

The prevalence of diabetes mellitus was $2.1 \%$ [95\% CI 1.25 - 2.96] in rural areas and 5.1\% [95\% CI: $3.80-$ 6.48 ] in urban areas (Figure 1). In rural areas, the prevalence was $1.7 \%$ among men and $2.6 \%$ among women. In urban areas, the prevalence was $4.3 \%$ among men and $5.6 \%$ among women. There was no statistically significant difference between males and females in rural and urban areas (Figures $1 \& 2$ ).

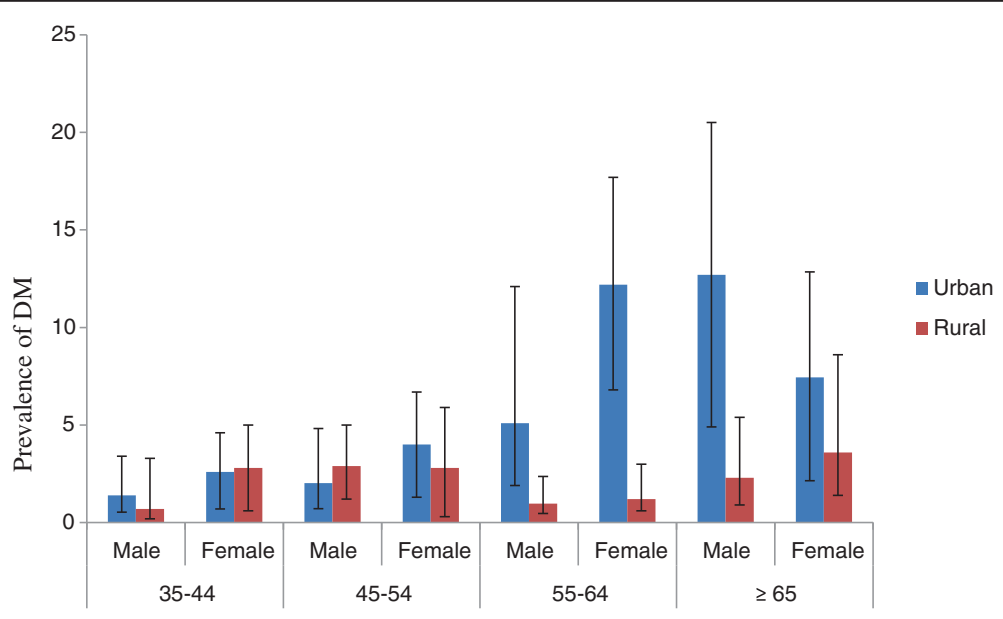

Figure 2 Prevalence of diabetes mellitus by Socio-demographic characteristics and residence of the study population among adults age 35 and above years, North West Ethiopia, 2012. 


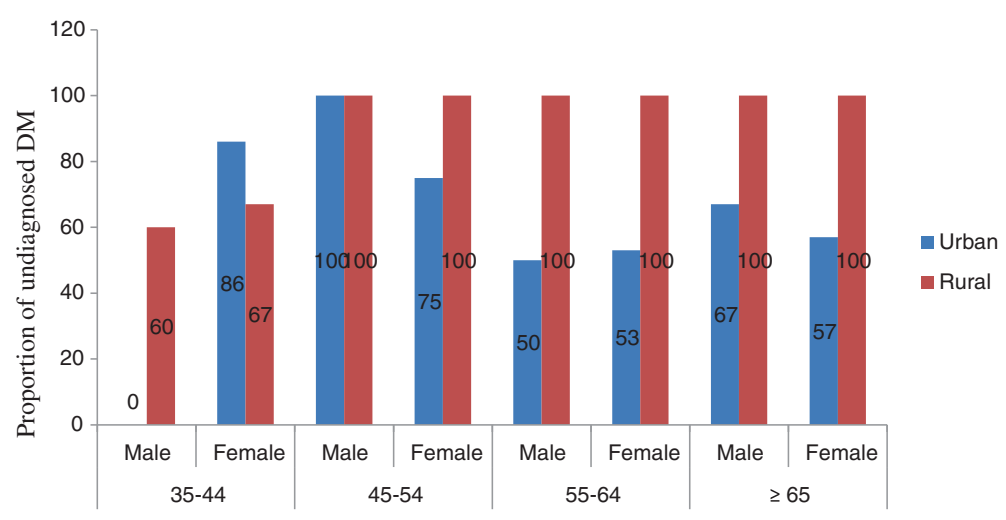

Figure 3 Previously undiagnosed diabetes mellitus by age, sex of the study population and residence among adults age 35 and above years, North West Ethiopia, 2012.

The proportion of previously undiagnosed DM was 53 (69\%); which was $82.6 \%$ (19 of 23) in rural areas and $63 \%$ (34 of 54) in urban areas. In the rural areas, the proportion of previously undiagnosed DM tended to rise as the age of the population increased (Figure 3).

The multivariate logistic regression analysis of factors associated with diabetes mellitus among the male and female sex is presented in Table 2. The logistic regression analysis done separately for urban and rural participants revealed associated risk factors. In the urban population, DM was significantly associated with family history of $\mathrm{DM} \quad(\mathrm{AOR}=5.05 ; 2.43,10.51)$, older age $(\mathrm{AOR}=4.86$; $1.99,11.9)$, and physical inactivity $(\mathrm{AOR}=1.92 ; 1.06$, 3.45). Alcohol consumption $(\mathrm{AOR}=4.16 ; 1.02,17.04)$ was inversely associated with diabetes mellitus in the rural population. Moderate alcohol drinking for the last 30 days was protective (AOR $=0.24,0.06,0.99)$ for DM (Table 3). After stratifying the data according to sex controlling for residence, age 65 and above was significantly associated with diabetes mellitus among males $(\mathrm{AOR}=3.55 ; 1.30,9.72)$. Family history of DM $(\mathrm{AOR}=$ $7.1 ; 3.07,16.25)$, physical inactivity (AOR $=2.1 ; 1.09$, 4.02 ) and age 55-64 (AOR $=2.2 ; 1.07,4.4)$, were significantly associated with diabetes mellitus among females (Tables 2 and 3).

\section{Discussion}

In this population-based cross-sectional study, we were able to measure the prevalence of diabetes among adults aged 35 years and older in rural and urban settings of northwest Ethiopia. We also uncovered that a large proportion of DM is undiagnosed and untreated in this population. The risk factors included family history of DM, older age and physical inactivity in the urban population and moderate alcohol drinking in the rural population.

A significant difference was observed in the prevalence of DM among urban and rural dwellers in the study area. The prevalence among the rural dwellers turned out to be very close to that of the rural dwellers in West Africa (2.6\%) [20]. Even though the prevalence among urban dwellers of this study is higher than that of rural dwellers, it is comparatively lower than the prevalence

Table 2 Multivariate analysis of factors associated with diabetes mellitus among male and female sex of Gondar, North West Ethiopia (2012)

\begin{tabular}{|c|c|c|}
\hline \multirow[b]{2}{*}{ Variable } & \multicolumn{2}{|c|}{ Adjusted OR $[95 \% \mathrm{Cl}]$} \\
\hline & Male & Female \\
\hline \multicolumn{3}{|l|}{ Age in year } \\
\hline $35-44$ & 1.00 & 1.00 \\
\hline $45-54$ & $1.00[0.31,3.24]$ & $1.28[0.54,3.03]$ \\
\hline $55-64$ & $1.33[0.34,5.25]$ & $2.72[1.24,5.97]$ \\
\hline$\geq 65$ & $3.55[1.30,9.72]$ & $2.29[0.92,5.70]$ \\
\hline \multicolumn{3}{|l|}{ Residence } \\
\hline Urban & 1.00 & 1.00 \\
\hline Rural & $0.84[0.25,2.77]$ & $1.57[0.48,5.09]$ \\
\hline \multicolumn{3}{|c|}{ Body mass index } \\
\hline $\mathrm{BMI}<25$ & 1.00 & 1.00 \\
\hline $\mathrm{BMI} \geq 25$ & $1.91[0.94,3.89]$ & $1.19[0.66,2.17]$ \\
\hline
\end{tabular}

At least moderate physical activity No $\quad 1.22[0.45,3.29] \quad 2.1[1.09,4.02]$ Yes

Family history of Diabetes Mellitus

Waist circumference

Low risk

1.00

1.00

High risk

$0.92[0.21,4.13] \quad 1.19[0.65,2.17]$

Alcohol consumed the last 30 days

No

1.00

1.00

Yes

$0.54[0.16,1.81] \quad 0.47[0.15,1.47]$ 
Table 3 Multivariate analysis of factors associated with diabetes mellitus among urban and rural residents of Gondar, North West Ethiopia (2012)

\begin{tabular}{|c|c|c|}
\hline \multirow[b]{2}{*}{ Variable } & \multicolumn{2}{|c|}{ Adjusted OR [95\% Cl] } \\
\hline & Rural & Urban \\
\hline \multicolumn{3}{|l|}{ Age in year } \\
\hline $35-44$ & 1.00 & 1.00 \\
\hline $45-54$ & $1.07[0.39,2.98]$ & $1.60[0.62,4.17]$ \\
\hline $55-64$ & $0.27[0.03,2.13]$ & $5.26[2.21,12.5]$ \\
\hline$\geq 65$ & $1.23[0.36,4.17]$ & $4.86[1.99,11.9]$ \\
\hline \multicolumn{3}{|l|}{ Sex } \\
\hline Male & 1.00 & 1.00 \\
\hline Female & $1.07[0.41,2.79]$ & $1.20[0.57,2.56]$ \\
\hline \multicolumn{3}{|c|}{ Body mass index } \\
\hline $\mathrm{BMl}<25$ & 1.00 & 1.00 \\
\hline $\mathrm{BMI} \geq 25$ & $0.64[0.23,1.79]$ & $1.19[0.66,2.17]$ \\
\hline \multicolumn{3}{|c|}{ At least moderate physical activity } \\
\hline No & 1.00 & 1.00 \\
\hline Yes & $0.62[0.15,2.65]$ & $0.52[0.29,0.94]$ \\
\hline \multicolumn{3}{|c|}{ Family history of Diabetes Mellitus } \\
\hline No & 1.00 & 1.00 \\
\hline Yes & $8.46[0.61,117]$ & $5.05[2.43,10.51$ \\
\hline \multicolumn{3}{|c|}{ Waist circumference } \\
\hline Low risk & 1.00 & 1.00 \\
\hline High risk & $1.45[0.75,2.81]$ & $1.04[0.54,2.00]$ \\
\hline \multicolumn{3}{|c|}{ Alcohol consumed the last 30 days } \\
\hline Yes & 1.00 & 1.00 \\
\hline No & $4.16[1.02,17.04]$ & $1.44[0.61,3.42]$ \\
\hline
\end{tabular}

* Adjusted for scio-demogrpahic, life style and anthropometric measurements.

seen among the Commercial Bank employees in Addis Ababa (6.5\%) [5] and a similar study done on urban dwellers of South Africa (12.1\%) [21]. Differences observed in diabetes prevalence estimates across studies might be due to the socio-demographic and life style differences in the localities studied. Literature shows that urbanization and economic development are increasing the prevalence of DM by about $40 \%[22,23]$.

The proportion of previously undiagnosed DM cases was alarmingly high in both urban and rural settings, although the rate is much higher in rural populations. A similar study in rural South Africa has also reported $84.8 \%$ of undiagnosed DM cases [10,24]. The high rate of these findings may reflect the low awareness of the public and primary health care providers about the disease [25].

In the current study, increasing age was an important risk factor for DM in urban areas which is consistent with other reports [26,27]. Since aging causes a progressive decline in the strength and endurance of musculature, which causes muscle atrophy, the risk of developing Type 2 DM increases.

Similarly, a study conducted in Puerta Rico showed that the prevalence of DM increased with age, with a peak prevalence in the urban oldest age-group [28]. The decrease in physical activity associated with city lifestyle partly explains the excess prevalence of diabetes mellitus in such groups. The variation could be explained by the differential distribution in risk factors between urban and rural dwellers across different age groups in populations. In rural settings, even older people are likely to be physically active compared to their urban counterparts. Moreover, our finding shows that a markedly high proportion of BMI was noted among older age urban dwellers. This exposure is likely to be responsible for the observed high rate of prevalence in this age group.

Studies show that individuals with a family history of diabetes are at increased risks for DM. In our findings, family history of DM was the major independent variable associated with DM in urban areas. This finding is consistent with other reports [29-31]. How genetic predisposition alone causes DM is not known, but life style and living environments within families are perhaps most likely to be the contributing factors [32].

Our finding is in agreement with studies from sub-Saharan Africa in indicating the beneficial effect of physical activity in reducing the risk of Type $2 \mathrm{DM}$ $[23,33,34]$. Also, a systematic review of prospective cohort studies shows that lack of physical activity of moderate intensity has a risk of Type 2 diabetes [35]. The reduction in physical activity associated with a more sedentary lifestyle in urban areas may partly explain the development of diabetes mellitus in these areas. Exercise has been shown to increase insulin-stimulated glycogen synthesis and increased muscle mass which can contribute to the beneficial effects of physical activity on insulin sensitivity [36].

Even though quantification of the dose and duration of alcohol was not made in this study, alcohol consumption was inversely associated with high fasting blood glucose among the rural study population. About $81 \%$ of the rural study population reported regular alcohol consumption. Rural populations in the study area prepare local beer known as tella. The preparation has no standards and the alcohol content is highly variable. Previous research has indicated that low to moderate alcohol consumption is associated with a decreased incidence of diabetes mellitus compared with lifetime abstainers [33,37-39]. Further study on alcohol consumption patterns and the alcohol content of locally prepared alcoholic drinks is important to clearly understand the association with diabetes.

The limitation of this study is that it was only a crosssectional design which might not show temporal 
relationships and thus the observed associations may not necessarily be causal. The inclusion of only adults above the age of 35 years could also affect the overall prevalence, and since the Ethiopian population has a very broad base, the likely effect is that the overall adult prevalence of diabetes is likely to be lower than we reported in this paper. We included the older age group to increase our chances of getting diabetic cases for the factor analysis due to the limitation in resources. Lack of some details on exposures such as alcohol consumption, and Khat chewing smoking is another limitation; although khat chewing and smoking are generally extremely low among adults of this age in the study area. Also some of the information was based on selfreporting which is subject to recall bias.

We were also not able to distinguish the various types of DM in this study. The sample size was not also sufficient to do rigorous and detailed analyses on the various risk factors. This study can be regarded an eye opener for studies on chronic diseases in rural population of Ethiopia and clearly indicates the need for further detailed research with sufficiently large sample sizes.

\section{Conclusion}

The prevalence of diabetes mellitus is considerably higher among urban dwellers compared to the rural population. Overall, a large majority of diabetic cases in the study identified were not previously diagnosed and treated. The proportion of undiagnosed diabetes was higher among the rural population. Appropriate actions need to be taken to avail diagnostic and treatment services in all health units to detect DM early and initiate appropriate preventive and supportive care before complications arise. Physical activity among urban dwellers is recommended.

\section{Competing interests}

The funders had no role in the study design, data collection, analysis, decision to publish, or in the preparation of the manuscript. The authors declare no competing interests.

\section{Authors' contributions}

SMA, YB, and AW conceived and designed the study. SMA analyzed the data and wrote the draft manuscript. AA commented on the manuscript. YB \& AW commented on the draft and approved the final manuscript. All authors read and approved the final manuscript.

\section{Acknowledgment \\ The authors would like to express their deepest and heartfelt thanks to all study subjects. We would also like to forward our deepest gratitude to the University of Gondar, The World Health Organization, and Addis Continental Institute of Public Health for funding and supporting this project. We appreciate Dr. Thomas Syre and Mr. Demeke Dessu of the University of Gondar for their editing assistance.}

\section{Author details}

'Department of Physiotherapy, College of Medicine and Health Sciences, University of Gondar, Gondar, Ethiopia. ${ }^{2}$ Addis Continental Institute of Public Health, Addis Ababa, Ethiopia. ${ }^{3}$ School of Public Health, Addis Ababa University, Addis Ababa, Ethiopia. ${ }^{4}$ World Health Organization, Country Office- Ethiopia, Addis Ababa, Ethiopia.
Received: 12 July 2013 Accepted: 27 January 2014

Published: 30 January 2014

\section{Reference}

1. Zaoui S, Biemont C, Meguenni K: Epidemiology of diabetes in urban and rural regions of Tlemcen (Western Algeria). Sante 2007, 17(1):15-21.

2. Shaw JE, Sicree RA, Zimmet PZ: Global estimates of the prevalence of diabetes for 2010 and 2030. Diabetes Res Clin Pract 2010, 87(1):4-14.

3. Whiting DR, Guariguata L, Weil C, Shaw J: IDF diabetes atlas: global estimates of the prevalence of diabetes for 2011 and 2030. Diabetes Res Clin Pract 2011, 94(3):311-321.

4. Gning SB, Thiam M, Fall F, Ba-Fall K, Mbaye PS, Fourcade L: Diabetes mellitus in sub-Saharan Africa: epidemiological aspects and management issues. Med Trop (Mars) 2007, 67(6):607-611.

5. Nshisso LD, Reese A, Gelaye B, Lemma S, Berhane Y, Williams MA: Prevalence of hypertension and diabetes among Ethiopian adults. Diabetes Metab Syndr 2012, 6(1):36-41.

6. Leena A, Ahmad MaJPC MD: Type 2 diabetes prevention: a review. ADA Clin Diabetes 2010, 28(2):53-59.

7. Seyoum B: Impotence in Ethiopian diabetic men. East Afr Med J 1998, 75(4):208-210.

8. Worku D, Hamza L, Woldemichael K: Patterns of diabetic complications at jimma university specialized hospital, southwest ethiopia. Ethiop J Health Sci 2010, 20(1):33-39.

9. Mengesha B, Abdulkadir J: Heritability of diabetes mellitus in Ethiopian diabetics. East Afr Med J 1997, 74(1):37-40.

10. Cowie CC, Rust KF, Byrd-Holt DD, Eberhardt MS, Flegal KM, Engelgau MM, Saydah SH, Williams DE, Geiss LS, Gregg EW: Prevalence of diabetes and impaired fasting glucose in adults in the U.S. population: National Health And Nutrition Examination Survey 1999-2002. Diabetes Care 2006, 29(6):1263-1268.

11. Central Statistical Authority: Summary and Statistical Report of the 2007 Population and Housing Census. Ethiopia: Central Statistical Authority; 2007. http://www.csa.gov.et/newcsaweb.

12. Tadesse T, Getachew A, Admassu M, Kebede Y, Awoke T, Melese T, Amsalu S, Alemu S, Andargie G, Wassie B, et al: Demographic and health survey at Dabat District in Northwest, Ethiopia report of the 2008 baseline survey. Ethiopian J Health Biomed Sci 2011, 4:1-4.

13. Muluneh AT, Haileamlak A, Tessema F, Alemseged F, Woldemichael K, Asefa M, Mamo Y, Tamiru S, Abebe G, Deribew A, et al: Population based survey of chronic non-communicable diseases at gilgel gibe field research center, southwest Ethiopia. Ethiop J Health Sci 2012, 22(S):7-18.

14. Luboshitzky R, Atar S, Qupti G, Tamir A, Dgani Y, Flatau E: Prevalence of diabetes mellitus and glucose intolerance in adult Ethiopian immigrants. Harefuah 1995, 128(7):406-408. 464

15. Longo-Mbenza B, Ngoma DV, Nahimana D, Mayuku DM, Fuele SM, Ekwanzala F, Beya C: Screen detection and the WHO stepwise approach to the prevalence and risk factors of arterial hypertension in Kinshasa. Eur I Cardiovasc Prev Rehabil 2008, 15(5):503-508.

16. Jaakkot Uomilehto Al, Johan GE: Prevention of type 2 diabetes mellitus by changes in lifestyle among subjects with impaired glucose tolerance. N Engl J Med Med 2001, 344(18):1343-1349.

17. Chobanian AV, Bakris GL, Black HR, Cushman WC, Green LA, Izzo JL Jr, Jones DW, Materson BJ, Oparil S, Wright JT Jr, et al: Seventh report of the Joint National Committee on Prevention, Detection, Evaluation, and Treatment of High Blood Pressure. Hypertension 2003, 42(6):1206-1252.

18. Grundy SM, Brewer HB Jr, Cleeman Jl, Smith SC Jr, Lenfant C: Definition of metabolic syndrome: Report of the National Heart, Lung, and Blood Institute/American Heart Association conference on scientific issues related to definition. Circulation 2004, 109(3):433-438.

19. Lau DC, Douketis JD, Morrison KM, Hramiak IM, Sharma AM, Ur E: Canadian clinical practice guidelines on the management and prevention of obesity in adults and children [summary]. CMAJ 2007 2006, 176(8):S1-S13.

20. Abubakari ARLW, Jones MC, Kirk A, Agyemang C, Bhopal RS: Prevalence and time trends in diabetes and physical inactivity among adult West African populations: the epidemic has arrived. Public Health 2009, 123(9):602-614.

21. Peer N, Steyn K, Lombard C, Lambert EV, Vythilingum B, Levitt NS: Rising diabetes prevalence among urban-dwelling black South Africans. PloS One 2012, 7(9):e43336. 
22. Ramachandran A, Mary S, Yamuna A, Murugesan N, Snehalatha C: High prevalence of diabetes and cardiovascular risk factors associated with urbanization in India. Diabetes Care 2008, 31(5):893-898.

23. Mbanya JC, Motala AA, Sobngwi E, Assah FK, Enoru ST: Diabetes in sub-Saharan Africa. Lancet 2010, 375(9733):2254-2266.

24. LR K: IDF and WHO initiatives to put diabetes on the health agenda in Africa. Diabetes Voice 2004, 49(2).

25. Hjelm K, Mufunda E: Zimbabwean diabetics' beliefs about health and illness: an interview study. BMC Int Health Hum Rights 2010, 10:7.

26. Consultation WI: Definition and Diagnosis of Diabetes Mellitus and Intermediate Hyperglycemia. Geneva, Switzerland: WHO Document Production Services; 2006.

27. Adelson $\mathrm{N}$ : The embodiment of inequity: health disparities in aboriginal Canada. Can J Public Health 2005, 96(Suppl 2):S45-61.

28. Garcia-Palmieri MR, Costas R Jr, Cruz-Vidal M, Cortes-Alicea M, Colon AA, Feliberti M, Ayala AM, Patterne D, Sobrino R, Torres R, et al: Risk factors and prevalence of coronary heart disease in Puerta Rico. Circulation 1970, 42(3):541-549.

29. Zein CO, Levy C, Basu A, Zein NN: Chronic hepatitis C and type II diabetes mellitus: a prospective cross-sectional study. Am J Gastroenterol 2005, 100(1):48-55.

30. Rouabhia S, Malek R, Bounecer H, Dekaken A, Bendali Amor F, Sadelaoud M, Benouar A: Prevalence of type 2 diabetes in Algerian patients with hepatitis C virus infection. World I Gastroenterol 2010, 16(27):3427-3431.

31. Danquah I, Bedu-Addo G, Terpe K, Micah F, Amoako YA, Awuku YA, Dietz E, van der Giet M, Spranger J, Mockenhaupt FP: Diabetes mellitus type 2 in urban Ghana: characteristics and associated factors. BMC Public Health 2012, 12:210.

32. Ferrannini E, Gastaldelli A, lozzo P: Pathophysiology of prediabetes. Med Clin North Am 2011, 95(2):327-339. vii-viii.

33. van Dam RM: The epidemiology of lifestyle and risk for type 2 diabetes. Eur J Epidemiol 2003, 18(12):1115-1125.

34. Norris SL, Zhang X, Avenell A, Gregg E, Schmid CH, Lau J: Long-term nonpharmacological weight loss interventions for adults with prediabetes. Cochrane Database Syst Rev 2005, 2, CD005270

35. Jeon CY, Lokken RP, Hu FB, van Dam RM: Physical activity of moderate intensity and risk of type 2 diabetes: a systematic review. Diabetes Care 2007, 30(3):744-752.

36. Goodyear LJ, Kahn BB: Exercise, glucose transport, and insulin sensitivity. Annu Rev Med 1998, 49:235-261.

37. Howard AA, Arnsten JH, Gourevitch MN: Effect of alcohol consumption on diabetes mellitus: a systematic review. Ann Intern Med 2004, 140(3):211-219.

38. van de Wiel A: Diabetes mellitus and alcohol. Diabetes Metab Res Rev 2004, 20(4):263-267.

39. Baliunas DO, Taylor BJ, Irving H, Roerecke M, Patra J, Mohapatra S, Rehm J: Alcohol as a risk factor for type 2 diabetes: a systematic review and meta-analysis. Diabetes Care 2009, 32(11):2123-2132.

doi:10.1186/1471-2458-14-97

Cite this article as: Abebe et al.: Diabetes mellitus in North West

Ethiopia: a community based study. BMC Public Health 2014 14:97.

\section{Submit your next manuscript to BioMed Central and take full advantage of:}

- Convenient online submission

- Thorough peer review

- No space constraints or color figure charges

- Immediate publication on acceptance

- Inclusion in PubMed, CAS, Scopus and Google Scholar

- Research which is freely available for redistribution 